\title{
The Relationship between Levels of Greenery and Landscaping at Track and Field Sites, Anxiety, and Sports Performance of Collegiate Track and Field Athletes
}

\author{
Jennifer DeWolfe ${ }^{1,3}$, T.M. Waliczek ${ }^{1,4,5}$, and J.M. Zajicek ${ }^{2}$
}

ADDITIONAL INDEX WORDS. human issues in horticulture, competitive state anxiety inventory-2

SUMMARY. Researchers wonder what it takes to improve athlete performance. Research has suggested that plants reduce anxiety, and reduced anxiety could, in turn, improve athletic performance. Research also shows that plants have psychological and restorative value such as improving coping mechanisms in human subjects as well as the potential to improve concentration and focus attention that could affect performance of athletes. The main objective of this research was to investigate the impact of greenery/landscaping on athletic performance and cognitive and somatic anxiety in track and field athletes. Four university track and field teams and 128 athletes participated in the study. Individual athlete performance and athletes' scores on the competitive state anxiety inventory-2 (CSAI-2) cognitive and somatic anxiety tests were collected from seven track meets that occurred during one spring competition season. Greenness/landscaping level was determined by Likert scale rating averages from professional horticulturists who individually rated each site. A regression analysis found that greenness level was a predictor $(P=0.000)$ of best performance by athletes. More of the athletes' best performance marks were at the track and field site that had the highest greenery rating, and many of the athletes' worst performance marks were achieved at the site that had the lowest greenery rating. Results also indicated that all athletes performed better at the more vegetated track and field site regardless of event and level of anxiety. All athletes performed similarly at each of the track and field sites regardless of ethnicity, gender, or grade classification. However, the overall average mean anxiety scores for all the athletes involved in this study were somewhat high in comparison with the instrument-normed scores for both the cognitive and somatic anxiety scales.

S ports performance has been constantly improving with new technology. Ideas and theories for improved training and new techniques and fresh drills have been developed to benefit the athlete and their performance ability (Raglin et al., 1990). Tactics include enhancing confidence and reducing athletes' anxiety for more compelling performances (Raglin et al., 1990). Research has also discovered that athletes' poor performance can sometimes be related to high levels of anxiety (Raglin and Turner, 1992).

Research has found a relationship between emotional stress and the consistency of individual competitive performance and that athletes with

\footnotetext{
${ }^{1}$ Department of Agriculture, Texas State University, San Marcos, TX 78666

${ }^{2}$ Professor, Department of Horticultural Sciences, Texas A\&M University, College Station, TX 778432133

${ }^{3}$ Graduate student

${ }^{4}$ Professor
}

${ }^{5}$ Corresponding author. E-mail: tcl0@txstate.edu. poor performance indicated more emotional stress when compared with the athletes with good performance (Turner and Raglin, 1995). Anxiety most often leads to uncontrollable feelings of inadequacy, worry, "butterflies in the tummy" feelings, rapid heartbeat, nervousness, and negativity. It can also produce positive or negative thoughts from present or past competitions, which affect the athlete's level of confidence in their abilities (Martens et al., 1990).

According to Martens (1977), anxiety is the reaction brought upon by an environmental demand and can be interpreted as intimidating by the individual. The multidimensional theory of anxiety has been given much attention because of the highly investigated relationship between anxiety and athletic performance (Krane and Williams, 1987). The athletes' performance decreases when anxiety levels are exceedingly high or when they fall below the normal range.

The optimum track and field performance anxiety levels vary depending upon the events' requirement for physical power and muscle mass increase (Raglin et al., 1990). Unlike distance running that only requires the athlete to run, events like shot put, pole vault, and triple jump require higher anxiety levels because the events have more elements involved with moving the body weight at the right time with the right force (Turner and Raglin, 1995). Track and field athletes have been said to be at their best performance when their anxiety level is high for middle distances $(200-400 \mathrm{~m})$ and low for short sprints $(100 \mathrm{~m})$ or long distances (1-2 miles) (Landers and Boutcher, 1986).

Athletes' anxiety can be defined and measured in two different ways: cognitive vs. somatic. Cognitive anxiety is related to an athlete's negative expectations, consequences of failure, and the evaluation of his/her ability relative to others. Cognitive anxiety has been shown to exert a strong influence on the performance of the athlete regardless of the individual athlete's physical ability (Humara, 2001). Cognitive anxiety has also been shown to cause negative concerns about performance, disrupted attention, and a lack of concentration. Somatic anxiety is associated more with physiological symptoms of anxiety, such as butterflies in the stomach, excessive sweating, shakiness, and muscle cramps (Krane and Williams, 1987; Martens et al., 1990). Studies have shown that, typically, better athletic performance is because of either low levels of cognitive anxiety and somatic anxiety or high levels of confidence (Krane and Williams, 1987; Martens et al., 1990; Rodrigo et al., 1990). An athlete's confidence has been said to be affected by his/her ability to use imagery for mental toughness and his/her ability to focus after a mistake (Abma et al., 2002).

\begin{tabular}{llll}
\hline $\begin{array}{l}\text { Units } \\
\begin{array}{l}\text { To convert U.S. to SI, } \\
\text { multiply by }\end{array}\end{array}$ & U.S. unit & SI unit & $\begin{array}{l}\text { To convert SI to U.S., } \\
\text { multiply by }\end{array}$ \\
\hline 0.3048 & $\mathrm{ft}$ & $\mathrm{m}$ & 3.2808 \\
1.6093 & $\operatorname{mile}(\mathrm{s})$ & $\mathrm{km}$ & 0.6214
\end{tabular}


Research has suggested psychological benefits from interactions with nature and green spaces. Hartig and Evans (1993) brought attention to theories focused on the positive effects of nature on human well-being. Studies have also suggested that plants affect people's quality of life and that plants promote positive thoughts when people are in the presence of plants (Larsen et al., 1998; Waliczek et al., 1996, 2005). Research has provided evidence that plants, trees, shrubs, and naturalized areas are beneficial to people by reducing stress and through the renewal of the mind (Ulrich, 1984). Natural settings have more restorative effects on people's emotional state in comparison with urban settings (Ulrich et al., 1991), which explains why wilderness areas or urban parks are often chosen by people for retreats during stressful times (Hartig and Evans, 1993). Positive feelings can be invoked through landscapes with natural elements like vegetation and water, which all help to reduce high stress to moderate levels (Fredrickson and Levenson, 1998). Natural scenes are known to be more restorative if human-made objects such as cars or buildings are inconspicuous or absent (Ulrich, 1983).

The main objective of this study was to determine if the level of greenery and landscaping at track and field competition sites influenced collegiate athletes' performance and/or anxiety levels.

\section{Materials and methods}

SAMPLE SCHOOLS AND ATHLETES. A total of 512 track and field athletes from 19 different universities within Texas were asked to participate in the study. Athletes who participated in the events of shot put, discus, hammer throw, and javelin field events were not invited to participate because their event placement most commonly occurs outside the track stadium, and therefore, they would not have viewed and been influenced by track and field landscaping. Athletes who participated in the following events were asked to participate in the study: triple jump, long jump, high jump, pole vault, sprints $(100 \mathrm{~m}, 200 \mathrm{~m}, 100$-m hurdles), mid-distance running $(400 \mathrm{~m}$, $400-\mathrm{m}$ hurdles, $800 \mathrm{~m})$, and long distance running $(1500 \mathrm{~m}, 3200 \mathrm{~m}$, $5000 \mathrm{~m}, 10,000 \mathrm{~m}$, steeplechase). Four different universities chose to participate and within those teams a total of
128 athletes agreed to participate in the study.

The schools and track and field teams were contacted through e-mail with a note detailing the study and how researchers would be using information from athletes. After 2 weeks, researchers sent another e-mail to encourage responses and followed up with phone calls to each coach. Researchers sent another short e-mail after phone conversations so that coaches could reply with their response on whether they did or did not want to participate.

Track AND FIELD sites. The track and field competition sites were chosen based on the track team schedule for all teams that agreed to participate in the study. Of all the track meets in which each of the four teams were participating during the Spring 2009 competition season, four locations included all participating teams in competition. Each of the track meets was a multiple team meet, which means that more than three different schools were at each meet competing against each other. Therefore, these sites/meets were those for which data were collected. The schools and Texas locations were University of Texas, Austin; Rice University, Houston; Stephen F. Austin University, Nacogdoches; and Texas Tech University, Lubbock.

Greenness rating scale. To measure the differing levels of greenness/landscaping at each track and field site, a Likert rating scale was used (Likert, 1967). The system of measurement was based on a reliable and valid greenness rating instrument that was used similarly in the previous research (Kuo and Sullivan, 2001). Each number on the scale related to a description explaining the levels/percentages of greenery and landscaped areas of the track and field competition site from the center of the field, accounting for only what the researcher could view from a $360^{\circ}$ area at each location. Each track and field site was rated on the levels of landscaping during the same period as the outdoor competition season. The Likert rating scale consisted of the following rating criteria: $\mathrm{l}=$ no greenery, traffic is visible, buildings are in view, only grass on field; 2 = minimal greenery, some turf, no shrubs, some views of buildings, $25 \%$ greenery; $3=$ minimal greenery, some turf and shrubs, few views of buildings, $50 \%$ greenery; $4=$ some greenery, turf, trees, and shrubs, no views of buildings, $75 \%$ greenery; and $5=$ fully landscaped around all perimeter of the track, viewings of trees or field scapes in the distance.

The researcher recorded information regarding the landscape from various angles including the middle of the field and from the stadium seating on both sides of the field if applicable, using photographs to document views. To maintain consistency in the study, the researcher was the sole photographer for recording the information at each site. Photographs were taken during competition season and at a time when people were not present such as early morning or just before sunset. The photographs of multiple views for each track and field site were viewed by three professional horticulturists from both academic and industrial backgrounds who privately and individually rated each landscape using the Likert scale. Scores resulted in an average greenery rating from each professional horticulturist for each track and field site. These scores from each of the three horticulturists were averaged together to result in one final composite score for each track meet site.

SOMATIC AND COGNITIVE ANXIETY INSTRUMENT. Somatic and cognitive anxiety was assessed using the CSAI-2 (Martens, 1977). The survey took 510 min for participants to complete and consisted of 18 statements (nine for the somatic anxiety scale and nine for the cognitive anxiety scale) regarding how each athlete felt while he/she competed in sporting events. The somatic anxiety scale questions pertained to feelings of tense muscles, butterflies in the stomach, and other physiological symptoms (Martens, 1977). The cognitive anxiety scale questions measured negative selfevaluation, negative expectations of success, and other mental components of anxiety (Martens, 1977). To respond, each athlete marked one of the following four answer choices: "not at all," "hardly ever," "sometimes," or "often." Athletes chose the answer which most pertained to their feelings/emotions at the time the survey was administered.

Scoring was determined through the allocation of 1, 2, 3, or 4 points for each of the responses available and chosen by the respondent. This resulted 
in a score ranging from 9 (low anxiety) to 36 (high anxiety) with separate totals for each of the scales. This instrument had been tested for reliability and validity (Martens, 1977) and normed on a nationwide sample of athletes. The published reliability for the cognitive anxiety instrument was 0.79 and for the somatic anxiety instrument was 0.82 (Martens, 1977).

SPORTS PERFORMANCE QUESTIONS. To measure the variable of sports performance, there was a space allocated at the bottom of the survey for each athlete to report his or her performance at each of the different track meets at the four different selected competition locations. For those athletes who did not return their surveys for each meet, the researcher used a live results webpage (Flash Results, 2011) for track and field competitions and recorded performance for each athlete for each meet. The researcher ranked all the listed performances for each athlete for the season as best, second best, third best, and lowest performance.

Demographic QUeSTIONNAIRE. A demographic questionnaire was created by the investigator using other known reliable and valid instruments as models (Dravigne et al., 2009) to obtain background information on each participant. The questionnaire inquired about each participant's gender, ethnicity, year of eligibility, main event in which the athlete was participating, university of attendance, best mark overall with year of performance and location, and each previous season of collegiate competition best mark and location.

DATA COLlECTION AND ANALYSIS. For this study, each athlete was asked to complete seven surveys throughout competition season, during the time span between $1 \mathrm{~h}$ before and $1 \mathrm{~h}$ after participation in their event at selected competitions. A chosen team member or coaching staff member was asked to collect all the written surveys after each selected meet and to return them to researchers in a preaddressed and stamped manila envelope. Data were entered into an Excel $^{\text {TM }}$ (Microsoft, Redmond, WA) spreadsheet and then downloaded into SPSS $®$ (version 17.0; SPSS, Chicago, IL) for statistical analysis. Data analyses included frequencies and descriptive tests, as well as regression tests, a chi square analysis, Pearson product-moment correlation tests, and analysis of variance
(ANOVA) tests to compare data between different groups of athletes.

\section{Results and discussion}

Of the 512 athletes who were asked to participate in the study, 128 participants $(26 \%)$ completed consent forms and provided demographic information. Participants were from the following Texas universities: Texas A\&M University, Corpus Christi (17.2\%); Texas Tech University, Lubbock (23.4\%); Stephen F. Austin University, Nacogdoches (38.3\%); and Texas State University, San Marcos
(21.1\%). The gender distribution was fairly evenly distributed with $55.5 \%$ female and $44.5 \%$ male respondents, yet varied in comparison with the overall distribution within National Collegiate Association of Athletics (NCAA), which had $55 \%$ male and $45 \%$ females (DeHass, 2009).

The study included $\approx 42.5 \%$ Caucasian athletes, 37.8\% African American athletes, 9.4\% Hispanic athletes, $1.6 \%$ Asian American athletes, and $8.7 \%$ athletes considering themselves as "other." Reports from NCAA for Division I track and field athletes showed the ethnicity

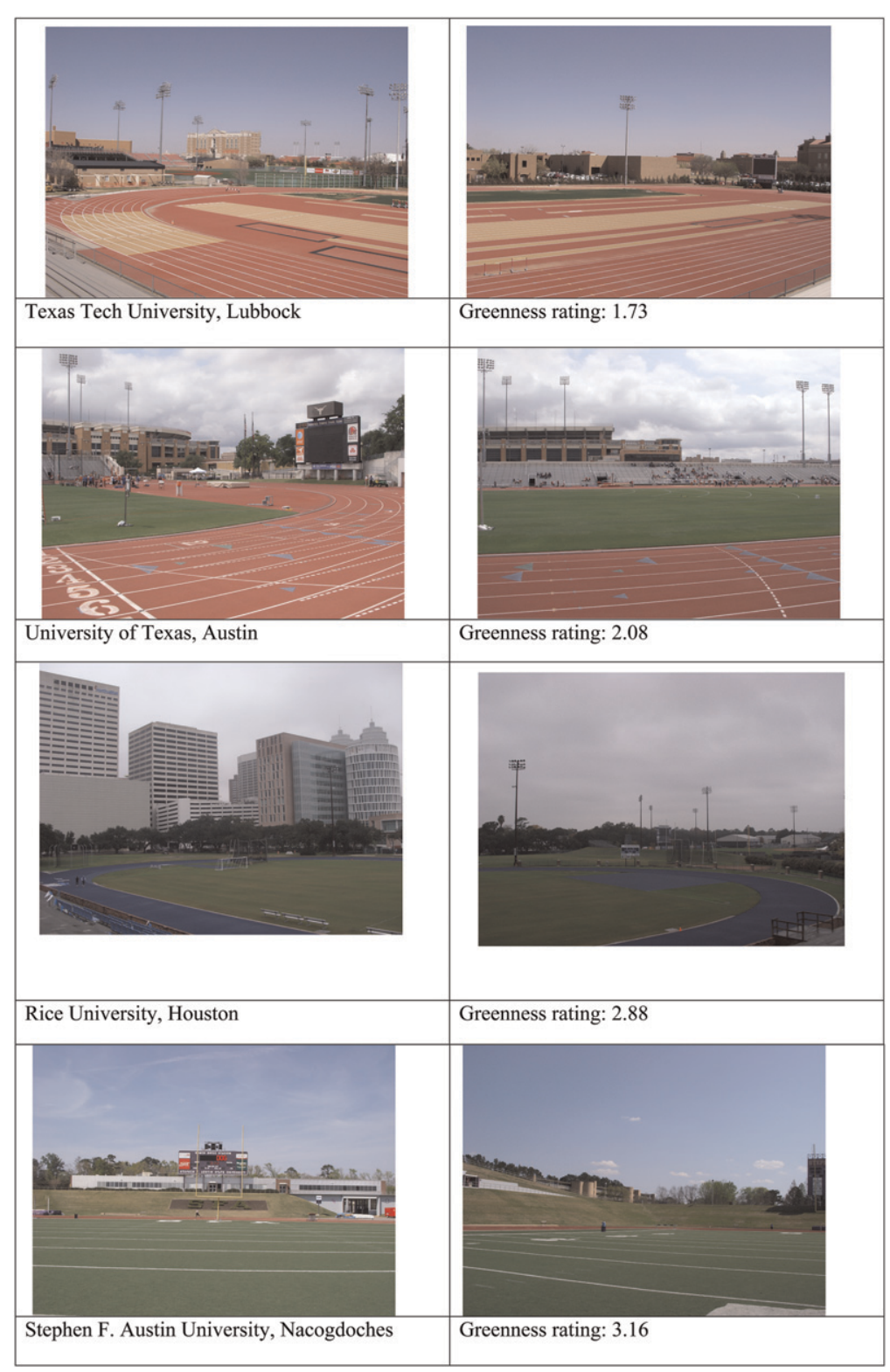

Fig. 1. Photographs and greenness/landscaping ratings of university track and field sites in Texas determined from average Likert scale mean ratings by professional horticulturists ( $1=$ no greenery, 5 = fully landscaped $)$ in the study of the relationship between levels of greenery/landscaping at track and field sites, anxiety, and sports performance. 
reports for the year of the study to be similar to the research participants except for that this research group included more minority group athletes (African American and Hispanic) and fewer Caucasian athletes (DeHass, 2009).

The athletes surveyed were grouped by their year of eligibility and included $32.8 \%$ freshman students, 28.2\% sophomore students, $20.6 \%$ junior level students, and $15.3 \%$ senior level students. Athletes were grouped according to the events in which they were competing, and only recorded data in one of the events in which they competed if they chose to participate in more than one event. There were four categories into which athletes were classified: $26.8 \%$ were placed in the triple, long, and high jump and pole vault; $16.5 \%$ participated in sprints $(100 \mathrm{~m}, 200 \mathrm{~m}$, 100 -m hurdles), and $31.5 \%$ competed in mid-distance running $(400 \mathrm{~m}, 400-\mathrm{m}$ hurdles, $800 \mathrm{~m}$ ). Lastly, 25.2\% were long distance runners $(1500 \mathrm{~m}, 3200 \mathrm{~m}$, $5000 \mathrm{~m}, 10,000 \mathrm{~m}$, steeplechase).

Greenness Ratings. Three horticulture professionals privately and individually rated each of the photographed track and field sites, and then scores for all three horticulturists were averaged to obtain an overall greenery rating for each site. A score of 5 for a field site was considered to have the highest level of greenery and a score of 0 was the lowest rating possible and had no greenery. Texas Tech University received a 1.73 greenery rating; University of Texas received a 2.08 greenery rating; Rice University received a 2.88 greenery rating, and Stephen F. Austin University received a 3.16 greenery rating (Fig. 1).

Athlete PERFORMANCE COMPARISONS. Performance was ranked with 1 being entered for the worst performance, 2 being entered for the third best performance, 3 being entered for the second best performance, and 4 for being entered for the best performance. A regression analysis was performed to determine if the presence of greenery on the track and field competition site was a predictor of better performance by athletes. The analysis indicated that greenness level was a predictor $(P=$ 0.000 ) of best performance by athletes when performance level of athletes was the dependent variable (Table 1 ). The researcher ranked all the listed performances for each athlete for the season lowest performance. Track and field sites with the highest ratings in greenness resulted in the greatest number of athletes achieving their best performances (Fig. 2).

Descriptive data based on performance verified results from the regression analysis. Performance data were collected from seven different track meets at four different locations. Not all the athletes who participated in the study participated in all seven track meets. Most of the athletes' best performance marks were at Stephen F. Austin University (47.7\%) which had the highest greenery rating (3.16), and most of the athletes' worst performance marks were achieved at Texas as best, second best, third best, and

Tech University (68\%) which had the lowest greenery rating (1.73) (Fig. 2).

A chi square analysis was used to examine performance and greenery data (Table 2). Statistically significant differences were found in the chi square analysis results, which indicated that the performance of the athletes who participated in the track meets differed from the expected results at each of four track and field meets that corresponded with each of the four sites included in the study (Table 2). The difference in expected and observed performance percentages supports the idea of greenery having an impact on performance. Of the athletes who participated in the meet, Texas Tech University showed statistically significant

Table 1. Results of a linear regression analysis using greenness/landscape rating as a predictor and performance level of athletes as the dependent variable in the study of the relationship between levels of greenery/landscaping at track and field sites, anxiety, and sports performance.

\begin{tabular}{|c|c|c|c|c|c|}
\hline $\begin{array}{l}\text { Greenness/landscape } \\
\text { rating }^{\mathrm{z}} / \text { performance }^{\mathrm{y}}\end{array}$ & df & $\begin{array}{c}\text { Mean } \\
\text { square }\end{array}$ & $R^{2}$ & F & $P$ \\
\hline Regression & 5 & 68.339 & 0.611 & 36.714 & 0.000 * \\
\hline Residual & 117 & 1.861 & & & \\
\hline Total & 122 & & & & \\
\hline
\end{tabular}

${ }^{\mathrm{z}}$ Greenness/landscaping level was determined by averages from ratings of professional horticulturists who individually rated each site and created a mean from the data at each site. Greenness was rated using a Likert scale of $1-5$, where $1=$ no greenery and $5=$ fully landscaped.

'Performance was established from comparison of all the athletes' marks during the study in Spring 2009 period. *Significant at $P=0.05$

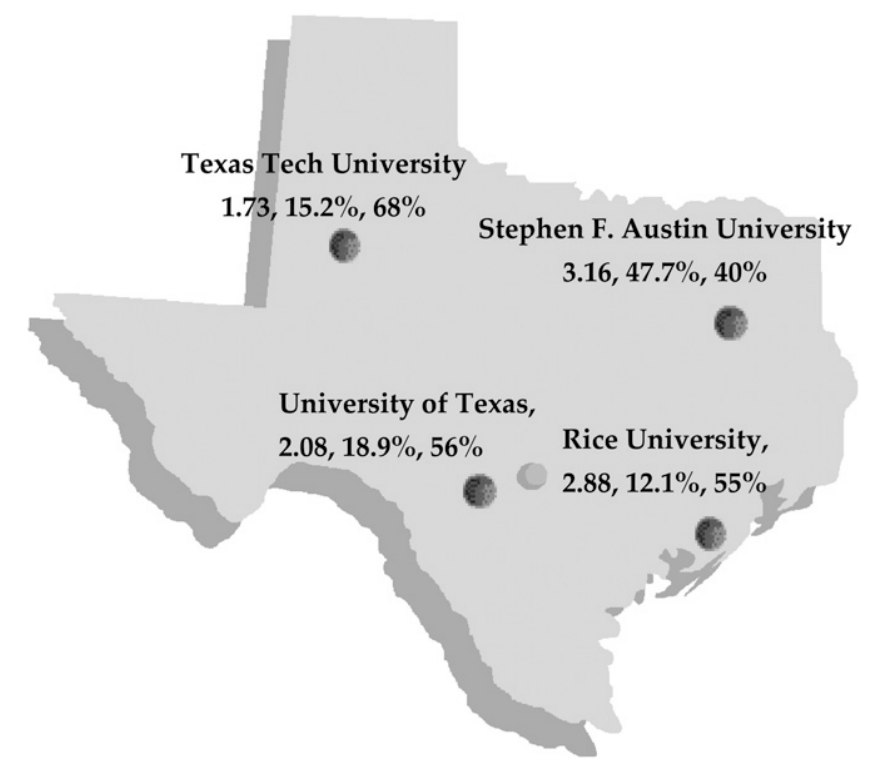

Fig. 2. Location of university track and field sites in Texas, greenness/landscaping ratings of the sites $(1=$ no greenery, $5=$ fully landscaped $)$, and percentage of athletes' best and poorest marks (established from comparison of all the athletes' marks during the Spring 2009 study period) at each site during the researched competition season in the study of the relationship between levels of greenery/ landscaping at track and field sites, anxiety, and sports performance. 
Table 2. Results of a chi square analysis comparing athletes' performance ${ }^{\mathrm{z}}$ at different track and field sites in Texas with varying greenness levels in the study of the relationship between levels of greenery/landscaping at track and field sites, anxiety, and sports performance.

\begin{tabular}{|c|c|c|c|c|c|}
\hline Track meet/attendance + mark & $\begin{array}{c}\text { Greenness } \\
\text { rating }^{\mathrm{y}}\end{array}$ & $\begin{array}{l}\text { Observed } \\
{[\text { no. }(\%)]}\end{array}$ & $\begin{array}{l}\text { Expected } \\
{[\text { no. }(\%)]}\end{array}$ & df & $P$ \\
\hline $\begin{array}{l}\text { Texas Relays, University of Texas, Austin } \\
\text { Attendance }+ \text { lowest mark } \\
\text { Attendance }+ \text { best mark } \\
\text { Total athletes attending meet }\end{array}$ & 2.08 & $\begin{array}{c}9(56.25) \\
3(18.75) \\
\quad 16\end{array}$ & $\begin{array}{l}4(25) \\
4(25)\end{array}$ & 3 & $0.029 *$ \\
\hline $\begin{array}{l}\text { Dogwood Relays, Stephen F. Austin University, } \\
\text { Nacogdoches } \\
\text { Attendance }+ \text { lowest mark } \\
\text { Attendance }+ \text { best mark } \\
\text { Total athletes attending meet }\end{array}$ & 3.16 & $\begin{array}{c}12(31.57) \\
5(13.15) \\
38\end{array}$ & $\begin{array}{l}9.5(25) \\
9.5(25)\end{array}$ & 3 & 0.064 \\
\hline $\begin{array}{l}\text { Rice Invite, Rice University, Houston } \\
\text { Attendance }+ \text { lowest mark } \\
\text { Attendance }+ \text { best mark } \\
\text { Total athletes attending meet }\end{array}$ & 2.88 & $\begin{array}{c}30(54.54) \\
9(16.36) \\
55\end{array}$ & $\begin{array}{l}13.8(25) \\
13.8(25)\end{array}$ & 3 & $0.000^{*}$ \\
\hline $\begin{array}{l}\text { Texas Tech Invite, Texas Tech University, } \\
\text { Lubbock } \\
\text { Attendance }+ \text { lowest mark } \\
\text { Attendance }+ \text { best mark } \\
\text { Total athletes attending meet }\end{array}$ & 1.73 & $\begin{array}{c}15(68.18) \\
4(18.18) \\
22\end{array}$ & $\begin{array}{l}5.5(25) \\
5.5(25)\end{array}$ & 3 & 0.000 * \\
\hline
\end{tabular}

${ }^{2}$ Best performance was established from comparison of all the athletes' marks during the Spring 2009 study period.

${ }^{y}$ Greenness/landscaping level was determined by averages from ratings of professional horticulturists who individually rated each site and created a mean from the data at each site. Greenness was rated using the following Likert scale of $1-5$, where $1=$ no greenery and $5=$ fully landscaped.

* Significant at $P<0.05$.

differences in expected $(25 \%)$ vs. observed $(68.18 \%)$ lowest marks and also had the lowest greenness ratings (1.73) $(P=0.000)$. Of the athletes who participated in the meet, Stephen F. Austin University was more closely aligned with best and poorest expected results $(20.8 \%, 20.8 \%)$ and observed results $(34.93 \%, 39.75 \%)$. Stephen F. Austin University also had the highest greenness rating (3.16) of all the track meet sites (Fig. 2; Table 2).

When athletes' anxiety levels are high or fall below normal range, athletes' performance can be negatively affected (Raglin et al., 1990). This study found that greenery appeared to be a predictor of best performance by athletes. Findings could be due to the greenery helping to reduce high stress levels of athletes and vegetation influencing the athletes' emotional states and ability to positively evaluate themselves during a high stress event. These findings support literature which has provided evidence that plants, trees, shrubs, and naturalized areas are beneficial to people through the renewal of the mind and by reducing stress (Ulrich, 1984). Other research has shown that there are restorative effects in natural settings compared with urban settings, which can positively affect people's emotional states (Ulrich et al., 1991) or help reduce high stress to moderate levels (Fredrickson and Levenson, 1998).

COMPARISONS OF COGNITIVE AND SOMATIC ANXIETY. Cognitive and somatic anxiety surveys (CSAI-2) were distributed at each of the seven track meets that were included within the study during the competition season. Researchers could not provide incentives to increase response rates of 
athletes because it would violate NCAA regulations. Therefore, there were a few responses with only 24 of the 128 athletes responding to the cognitive and somatic anxiety surveys for a $30.7 \%$ response rate. In comparison with norm samples, which were obtained from researchers who have conducted independent competitive anxiety research with the sport of track and field using the CSAI-2 (Martens, 1977), the overall average mean scores for all the athletes at all the meets were somewhat high for both the cognitive and somatic anxiety scores. The average norms recorded from all the track and field athletes across the nation were 20.34 for cognitive anxiety and 18.73 for somatic anxiety (Martens, 1977) with mean scores recorded for the athletes involved in this study being 22.52 for cognitive anxiety and 26.03 for somatic anxiety. As response rates were low and all track and field sites were not represented, no other statistical comparisons could be made among athletes and demographic groups.

COMPARISONS OF LOW VS. HIGH ANXIETY. Events were coded based on past research that formed the idea that athletes perform best under particular circumstances in regard to anxiety levels (Landers and Boutcher, 1986). Those events considered to be "high anxiety" events were mid-distance running events $(400 \mathrm{~m}, 400-\mathrm{m}$ hurdles, $800 \mathrm{~m}$ ). Those events known to be events where athletes perform well under low anxiety included sprints $(100 \mathrm{~m}$, $200 \mathrm{~m}, 100$-m hurdles) and long distance running events $(1500 \mathrm{~m}, 3200 \mathrm{~m}$, $5000 \mathrm{~m}, 10,000 \mathrm{~m}$, steeplechase). Events such as triple, long, and high jump and pole vault were included in the study that did not fall into either of the anxiety performance categories because anxiety was not known to be as influential in athlete performance (Landers and Boutcher, 1986).

A regression analysis was conducted to determine whether the presence of greenery was a predictor of best performance by athletes in events that were considered to be those in which athletes perform best under low anxiety, high anxiety, or in events where anxiety is not known to be as influential in performance (Table 3 ). Performance data were collected from seven different track meets at four different locations. Not all the athletes who participated in the study participated in all seven track meets. Statistically significant results supported the previous performance findings in this study from all athlete performance data that better performance occurred at the track and field site with more vegetation (Table 3 ). As were split based on type of event/preferred level of anxiety, results from this study indicated that all athletes performed better at the more vegetated track and field site regardless of event and level of anxiety that past research has indicated might be beneficial for best performance for that event (Fredrickson and Levenson, 1998).

DifFERENCES IN DEMOGRAPHIC Groups. A univariate ANOVA was run to compare athletes' best performance and the variables of gender, ethnicity, and grade classification to observe whether any particular demographic group benefitted more from the presence of greenery/landscaping in terms of performance in comparison with other groups. No differences were found in comparisons. All athletes performed similarly at each of the track and field sites regardless of ethnicity, gender, or grade classification. Therefore, all athletes and groups of athletes appeared to have the greatest the results did not change when data

number of best performance marks at the site with more vegetation and the greatest number of poor performance marks at the site with the least vegetation. Cognitive and somatic anxiety responses were limited and, therefore, statistical comparisons could not be made based on demographic groups and overall anxiety levels.

\section{Conclusions}

Trade magazines have shown that of all maintenance funds invested in university budgets, $\approx 20 \%$ are spent on maintaining the campus' landscape (Yahres, 2000) and only a percentage of that may be allocated toward the track and field competition area. These findings indicate the potential benefits of plants on athletic performance, perhaps justifying an increase in percentage of funds allocated for landscaping. The results also indicate a connection between athletic performance and levels of greenness or landscaping within track and field areas. Further research should examine the effect of greenery/landscaping on other sports performance.

The initial intent of the study was to determine if levels of greenery and landscaping influenced anxiety levels

Table 3. Results of a linear regression analysis comparing low anxiety, high anxiety, and not applicable anxiety events where greenness/landscape rating was used as a predictor, and performance level within the various events by preferred anxiety level was used as the dependent variable in the study of the relationship between levels of greenery/landscaping at track and field sites, anxiety, and sports performance.

\begin{tabular}{lrrrrr}
\hline $\begin{array}{l}\text { Greenness/landscape rating } \\
\text { best performance }\end{array}$ & df & $\begin{array}{c}\text { Mean } \\
\text { square }\end{array}$ & $\boldsymbol{R}^{2}$ & F & $\boldsymbol{P}$ \\
\hline Low anxiety events & & & & & \\
$\quad$ Regression & 1 & 48.973 & 0.271 & 14.160 & $0.001^{*}$ \\
$\quad$ Residual & 38 & 3.459 & & & \\
$\quad$ Total & 39 & & & &
\end{tabular}

High anxiety eventsw

$\begin{array}{lrrrrr}\text { Regression } & 1 & 33.726 & 0.164 & 9.806 & 0.003^{*} \\ \text { Residual } & 50 & 3.439 & & & \\ \text { Total } & 51 & & & & \end{array}$

Anxiety events not applicablev

\begin{tabular}{lrrrrr} 
Regression & 1 & 39.496 & 0.228 & 8.883 & $0.006^{*}$ \\
Residual & 30 & 4.446 & & & \\
Total & 31 & & & & \\
\hline
\end{tabular}

${ }^{2}$ Greenness/landscaping level was determined by averages from ratings of professional horticulturists who individually rated each site and created a mean from the data at each site. Greenness was rated using the following Likert scale of $1-5$, where $1=$ no greenery and $5=$ fully landscaped.

yBest performance was established from comparison of all the athletes' marks during the Spring 2009 study period. xThose events where athletes perform well under low anxiety included sprints $(100 \mathrm{~m}, 200 \mathrm{~m}, 100$-m hurdles $)$ and long distance running events $(1500 \mathrm{~m}, 3200 \mathrm{~m}, 5000 \mathrm{~m}, 10,000 \mathrm{~m}$, steeplechase $) ; 1 \mathrm{~m}=3.2808 \mathrm{ft}$.

wThose events considered to be "high anxiety" events were mid-distance running events $(400 \mathrm{~m}, 400$-m hurdles, $800 \mathrm{~m}$ ). vEvents such as triple, long, and high jump and pole vault were included in the study that did not fall into either of the anxiety performance categories because anxiety was not known to be as influential in athlete performance.

* Significant at $P<0.05$. 
and performance of athletes, so that relationships between variables could be examined more closely as other past research determined that views of nature reduced anxiety levels of research subjects. Low response rates on the anxiety inventory limited findings for this research but offer opportunities for future research. Further research is also necessary to determine if the type of landscaping or vegetation is influential, or if wooded or weedy natural areas would impact athletic performance more or less positively when compared with the designed landscape. This study was limited in that the athletes who were included in the research selfselected themselves for inclusion in the study, and therefore, results are not necessarily generalizable to the overall population of athletes. It is recommended that more research be conducted with a larger, randomly selected sample.

\section{Literature cited}

Abma, C., M. Fry, Y. Li, and G. Relyea. 2002. Differences in imagery content and imagery ability between high and low confident track and field athletes. J. Appl. Sport Psychol. 14:67-75.

DeHass, D. 2009. Student-Athlete Ethnicity Report. 17 Mar. 2011. <http://www. ncaapublications.com/productdownloads/ SAEREP10.pdf $>$.

Dravigne, A., T. Waliczek, R. Lineberger, and J. Zajicek. 2009. The effects of live plants and window views of green spaces on employee perceptions of job satisfaction. HortScience 43:183-187.

Flash Results. 2011. Flash Results, Inc. 17 Mar. 2011. <http://www.flashresults.com/>.

Fredrickson, B. and R. Levenson. 1998. Positive emotions speed recovery from the cardiovascular sequelae of negative emotions. Cogn. Emotion 12:191-220.
Hartig, T. and G.W. Evans. 1993. Psychological foundation of nature experience, p. 427-457. In: T. Garling and R.G. Golledge (eds.). Behavior and environment: Psychological and geographical approaches. North Holland, Amsterdam, The Netherlands.

Humara, M. 2001. The Relationship Between Anxiety and Performance: A CognitiveBehavioral Perspective. Athletic Insight 1. 3 Dec. 2009. <http://athleticinsight.com/ VollIss2/Cognitive_Behavioral_Anxiety. htm>.

Krane, V. and J.M. Williams. 1987. Performance and somatic anxiety, cognitive anxiety and confidence changes prior to competition. J. Sport Behav. 10:47-56.

Kuo, F. and W. Sullivan. 2001. Environment and crime in the inner city: Does vegetation reduce crime? Environ. Behav. 33:343-367.

Landers, D.M. and S.H. Boutcher. 1986. Arousal-performance relationships, $\mathrm{p}$. 163-184. In: J.M. Williams (ed.). Applied sport psychology: Personal growth to peak performance. Mayfield Publishing, Palo Alto, CA.

Larsen, L., J. Adams, B. Deal, B.S. Kweon, and E. Tyler. 1998. Plants in the workplace: The effects of plant density on productivity, attitudes, and perceptions. Environ. Behav. 30:261-281.

Likert, R. 1967. The method of constructing an attitude scale, p. 90-95. In: M. Fischbein (ed.). Readings in attitude theory and measurement. Wiley, New York.

Martens, R. 1977. Reactions to Norman Endler's "interaction model of anxiety," p. 352-358. In: D.M. Landers and R.W. Christiana (eds.). Psychology of motor behavior and sport. Human Kinetics, Champaign, IL.

Martens, R., R. Vealey, and D. Burton. 1990. Competitive anxiety in sport. Human Kinetics, Champaign, IL.
Raglin, J., W. Morgan, and K. Wise. 1990. Pre-competition anxiety and performance in female high school swimmers: A test of optimal function theory. Intl. J. Sports Med. 11:171-175.

Raglin, J.S. and P.E. Turner. 1992. Predicted, actual, and optimal pre-competition anxiety in adolescent track and field athletes. Scand. J. Med. Sci. Sports 2:148152 .

Rodrigo, G., M. Lusiardo, and G. Pereira. 1990. Relationship between anxiety and performance in soccer players. Intl. J. Sport Psychol. 21:112-120.

Turner, P.E. and J.S. Raglin. 1995. Variability in precompetition anxiety and performance in college track and field athletes. Med. Sci. Sports Exerc. 3:378-385.

Ulrich, R. 1984. View through a window may influence recovery from surgery. Science 224(4647):420-421.

Ulrich, R., R. Simons, E. Losito, M. Miles, and M. Zelson. 1991. Stress recovery during exposure to natural and urban environments. J. Environ. Psychol. 11:201-230.

Ulrich, R.S. 1983. Aesthetic and affective response to natural environment, p. 85125. In: I. Altman and J.F. Wohlwill (eds.). Human behavior and environment: Advances in theory and research. Plenum, New York.

Waliczek, T.M., J.M. Zajicek, and R.D. Lineberger. 2005. The influence of gardening activities on consumer perceptions of life satisfaction. HortScience 40:1360-1365.

Waliczek, T.M., R.H. Mattson, and J.M. Zajicek. 1996. Psychological benefits of community gardening. J. Environ. Hort. 14:204-209.

Yahres, M. 2000. What should stay put? Campus landscape planning for the long term. Facilities Manager Mag. 16(5):35-38. 